\title{
Genetic and Antigenic Analysis of Adenovirus Type 3 Strains Showing Intermediate Behavior in Standard Seroneutralization Test
}

\author{
Márcia TB Moraes, Messias da Silva, José Paulo G Leite, \\ Jussara P Nascimento ${ }^{+}$
}

Departamento de Virologia, Instituto Oswaldo Cruz, Av. Brasil 4365, 21045-900 Rio de Janeiro, RJ, Brasil

During an epidemiological survey of acute respiratory infection in Rio de Janeiro, among 208 adenovirus isolates, we found two strains that we were not able, by a standard neutralization procedure, to distinguish between type 3 or 7. However, DNA restriction pattern for the two strains with different enzymes were analyzed and showed a typical Ad3h profile. Using a cross-neutralization test in which both Ad3p and Ad7p antisera were used in different concentration against 100 TCID $_{50}$ of each adenovirus standard and both isolates, we were able to confirm that the two isolates belong to serotype 3. An hemagglutination inhibition test also corroborated the identification of both strains as adenovirus type 3. Comparing Ad3h and Ad3p genome, we observed 16 different restriction enzyme sites, three of which were located in genomic regions encoding polypeptides involved in neutralization sites.

Key words: adenovirus type 3 - genetic and antigenic analysis

Adenoviruses are important human patogens being responsible by several different clinical and epidemiological presentations depending on the serotype (Horwitz 1996). Human adenoviruses were classified in six different subgroups (A-F) and adenovirus belonging to the same subgroup frequently show cross reaction when typing virus by standard seroneutralization. To overcome this problem, some authors have proposed the use of resctriction enzyme patterns associated to seroneutralization (Adrian et al. 1986). Although occurring in all adenovirus subgroups, cross reactivity has been mainly reported within the subgroup $B$ regarding Ad3 and Ad7 new isolates (Matumoto et al. 1958, Fukumi et al. 1961, Rafajko 1967). Recently, Kayon et al. (1990) reported strains isolated in Argentina that were neutralized by Ad3 antiserum, showing a restriction enzyme pattern intermediate between $\mathrm{Ad} 3$ and $\mathrm{Ad} 7$ and they concluded that it was a new variant of $\mathrm{Ad} 3$, namely Ad3f. This same genotype was found to become prevalent in Chile during 1986 (Kayon \& Suarez 1990). Later, Niel et al. (1991) working with adenovirus type 3 and 7 isolated in Argentina, described a new Ad7 variant, namely Ad7h. Both variants described by Kayon and Niel are now rec-

This work was partially supported by CNPq, CAPES and FAPERJ, Brazil.

+ Corresponding author. Fax: 55-21-564.7638

Received 25 July 1997

Accepted 29 October 1997 ognized (Kayon \& Wadell 1992) as the same virus and belonging to serotype 7, genetic type $7 \mathrm{~h}$.

Type-specific antigenic determinants are present in three different proteins from adenovirus capsid: hexon, fiber and penton-base (Horwitz 1996). The protein found in adenovirus fiber mediates agglutination of red blood cells from monkeys and rats, depending on the adenovirus subgroup (Rosen 1960, Norby 1969, Philipson et al. 1975). This property can also be used to distinguish adenovirus subtypes through a hemagglutination inhibition assay (Hierholzer 1995).

During an eleven years acute respiratory infection (ARI) survey done in Rio de Janeiro we found two, among 208 adenovirus isolates, impossible to distinguish between Ad3 and Ad7 in a standard neutralization test. The restriction enzyme patterns from these two isolates and Ad 3h, Ad3p and Ad7p were prepared and data compared to the profiles existing in the literature.

\section{MATERIALS AND METHODS}

Adenovirus isolates - Two isolates were obtained by standard procedures described before (Nascimento et al. 1991) from nasopharyngeal secretions colected from under five year old children, presenting ARI classified as lower respiratory tract infection (LRTI), during the months of April and August 1990.

Adenovirus standards, strains and antisera Ad3p and Ad7p, Ad7a, Ad7b were obtained from VRD/CPHL,U.K. Ad7e was the original strain isolated in Brazil (Wadell et al. 1985) and Ad3h and 
Ad7h were the original strains isolated in Argentina (Niel et al. 1991). Ad3 and Ad7 rabbitt antisera were obtained from VRD/CPHL and also from MRC, Mill Hill, UK.

Adenovirus neutralization test - To type adenovirus recently isolated strains antisera for Ad types $1,2,3,4,5,6$, and 7 obtained from VRD/CPHL, U.K. were used following standard protocols (Hierholzer 1995). To discriminate among Ad3 and Ad7 for the strains classified as intermediate a cross neutralization test was designed in which different $A d 3 p$ and $A d 7 p$ antisera concentrations were tested against $100 \mathrm{TCID}_{50}$ of both recent isolates and Ad3p and Ad7p standard strains, using antisera provided by MRC, Mill Hill, UK.

Adenovirus hemagglutination and hemagglutination inhibition tests - The protocol described by Hierholzer (1995) was used. To discriminate among $\mathrm{Ad} 3$ and $\mathrm{Ad} 7$ a cross hemagglutination inhibition test was designed in which different Ad3p and $\mathrm{Ad} 7 \mathrm{p}$ antisera concentrations were tested against four hemagglutinating units (HAU) of both recent isolates and $\mathrm{Ad} 3 \mathrm{p}$ and $\mathrm{Ad} 7 \mathrm{p}$ standard strains, using antisera provided by MRC, Mill Hill, UK. These antisera were previously absorbed to rhesus monkey red blood cells.

Viral DNA extraction and restriction enzyme digestion - DNAs were prepared for each strain using the technique described by Hirt (1967) and modified by Wadell and de Jong (1980). DNAs were digested with the following endonucleases
BamHI, SmaI, HindlII, and EcoRI, for Ad7p, Ad7a, Ad7b and Ad7e and BamHI, BglII and XbaI for Ad3h. After digestion DNA fragments were analyzed in $1 \%$ or $2 \%$ agarose gels by horizontal electrophoresis in TBE buffer. DNA fragments were then vizualized under UV after staining with ethidium bromide $(0.5 \mu \mathrm{g} / \mathrm{ml})$. Photographs were obtained using Polaroid film 665 or 667.

Restriction maps used for comparison - The choice of restriction enzymes was based on site distribution along adenovirus genome. Restriction maps of Ad3p and Ad3h DNA for the endonucleases BamHI, BclI, EcoRI, HindlII, KpnI, SalI and $S m a I$ were obtained from Niel et al. (1991). Restriction maps for Ad7p and Ad7b with BamHI, $B c l \mathrm{I}, B g l \mathrm{II}, B s t$ EII, EcoRI, HindlII, SmaI, HpaI and $X b a \mathrm{I}$; for Ad7a with BamHI, HindllI, and BglII and for Ad7e with BstEII, EcoRI, HindlII, SmaI, $H p a \mathrm{I}$ and $X b a \mathrm{I}$ were obtained from Adrian et al. (1989), Li and Wadell (1986), Niel et al. (1991) and Wadell et al. (1981).

\section{RESULTS}

Two adenovirus strains isolated from unrelated patients during 1990 (104/90 and 396/90) could not be identified by the usual procedures employed for adenovirus serotyping and were considered as intermediates between Ad3 and Ad7. Viral DNA from both strains when analyzed by restriction nuclease digestion with BamHI, XbaI and BglII, showed a typical pattern of genomic type Ad3h

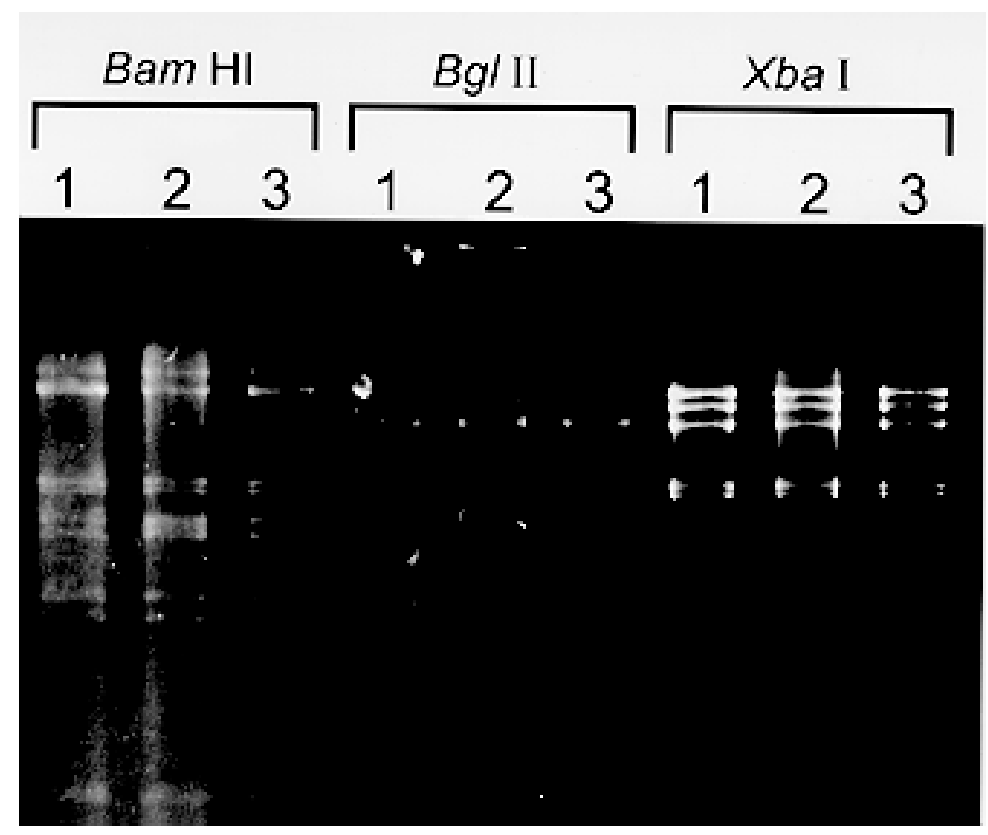

Fig. 1: restriction enzyme patterns for standard Ad3h (1) and strains 104/90 (2) and 396/90 (3). DNA was prepared for each strain and digested with endonucleases BamHI, $B g l \mathrm{II}$ and $\mathrm{XbaI}$, then electrophoresed in a $1 \%$ agarose gel in TBE buffer and ethidium bromide stained. Ad3h and both recent isolates showed the same profile for the three restriction endonucleases. 
(Fig. 1). The confirmation that the strains belonging to type 3 were obtained in a neutralization test comparing both Ad isolates to Ad3p and Ad7p standard virus against antisera prepared to Ad3p and Ad7p. As shown in Table I, standard strains were neutralized by homologous antisera up to $1 / 1600$ dilution, no reaction was seen between heterologous standard strains and antisera. Recent isolates were neutralized by Ad3 antiserum until 1/1600 (104/90) and 1/400 (396/90), and strain 104/90 showed also a cross reactivity with Ad7p antisera until 1/400 dilution, although strain 396/90, reacting weakly with $\mathrm{Ad} 3$ antiserum, did not show this cross reactivity. Table II shows hemagglutination inhibition test for both adenovirus isolates. There was no cross reactivity with $\mathrm{Ad} 7 \mathrm{p}$ antiserum and they reacted equally with the Ad3p antiserum. Fig. 2 shows the comparison of Ad3h with Ad3p genome and the different rectriction enzyme sites found for the two variants. At least 16 sites were different. The regions where these sites are located and some of the genomic products for these regions are also shown in Fig. 2.

\section{TABLE I}

Neutralization titer of adenovirus types 3 and 7 antisera tested against $100 \mathrm{TCID}_{50}$ of each virus strain

\begin{tabular}{lllll}
\hline & \multicolumn{4}{c}{ Adenovirus strains } \\
\cline { 2 - 5 } Antisera & Ad3p & Ad7p & $104 / 90$ & $396 / 90$ \\
\hline Ad3p & $>1600$ & $<50$ & $>1600$ & 400 \\
Ad7p & $<50$ & $>1600$ & 400 & $<50$ \\
\hline
\end{tabular}

$\mathrm{TCID}_{50}$ was calculated after incubation of infected HEp2 cells during seven days at $33^{\circ} \mathrm{C}$.

\section{TABLE II}

Hemagglutination inhibition titer of adenovirus types 3 and 7 antisera against 4 HUA of each virus strain

\begin{tabular}{lllll}
\hline & \multicolumn{4}{c}{ Adenovirus strains } \\
\cline { 2 - 5 } Antisera & Ad3p & Ad7p & $104 / 90$ & $396 / 90$ \\
\hline Ad3p & 5120 & $<20$ & 10240 & 5120 \\
Ad7p & $<20$ & 2560 & $<20$ & $<20$ \\
\hline
\end{tabular}

\section{DISCUSSION}

We have isolated two adenovirus strains that could not be serologicaly typed by standard neutralization test, as they were equaly neutralized by antisera to Ad3 or Ad7. Strains showing these features had been previously classified as intermediates (Matumoto et al. 1958, Fukumi et al. 1961, Rafjko 1967). Using viral DNA digestion with restriction enzymes and comparing with $\mathrm{Ad} 3$ and Ad7 maps described earlier, it was possible to classify these isolates as $\mathrm{Ad} 3$ variant $\mathrm{Ad} 3 \mathrm{~h}$, recently described in one isolate from Argentina (Niel et al. 1991).

Our two isolates were confirmed as $\mathrm{Ad} 3$ by seroneutralization using different antisera concentrations and virus strains, although strain 104/90 showed a higher reactivity than $396 / 90$, and being more similar to Ad3p.

This is the first report of Ad3h isolates in Brazil. Ad3 genomic types previously described in Brazil were Ad3p1 (Li \& Wadell 1988), Ad3e1 (Gomes et al. 1989) and Ad3e2 (Niel et al. 1991). These isolates were obtained from faecal specimens.

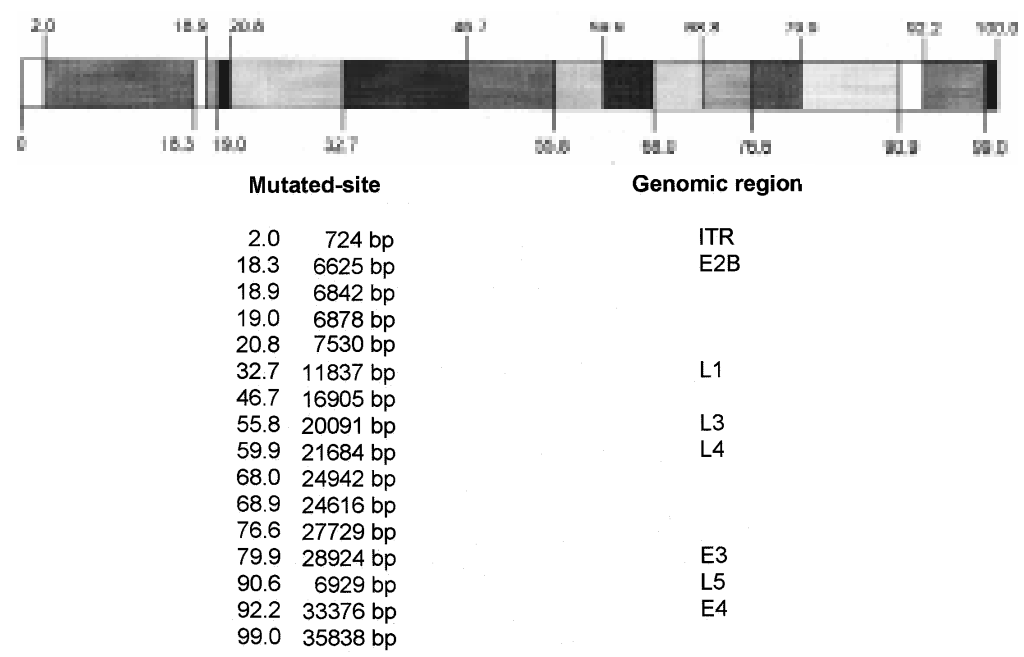

Fig. 2: location of differences in restriction enzyme sites for genomic type Ad3h in relationship to Ad3p.The existing homology between type 3 and type 7 (Garon et al. 1973) was considered for detailed 30\% of genome in which we found mutations in genomic type Ad3h. Information about 0 to $30 \%$ of Ad7 genome, between 67 to $69 \%$ of Ad5 map, and 70 to $100 \%$ of Ad2 map were obtained from van Ormondt and Galibert (1984). For the remaining 30 to $60 \%$ were used Ad2 map (Broker 1984). L (late), E (early) and ITR (inverted terminal repeat); bp is base pair, $1 \%$ of genome is $362 \mathrm{bp}$. 
It should be noticed that the $\mathrm{Ad} 3 / \mathrm{Ad} 7$ intermediate described in Japan (Matumoto et al. 1958) although it could not be identified as Ad3 or Ad7 by seroneutralization (Matumoto et al. 1958, Fukumi et al. 1961, Rafajko 1967) it was later shown to be Ad3 by hemagglutination inhibition (Adrian \& Wingand 1986). Our two Ad3h isolates were easily identified as Ad3 by the hemagglutination inhibition test. No difference was found in antisera reactivity for both strains and Ad3p prototype.

Due to the high frequency of occurrence of Ad3/Ad7 intermediate strains Tibbetts (1977) did an evaluation of the physical organization of $\mathrm{Ad} 3$ and $\mathrm{Ad} 7$ genomes using restriction endonucleases patterns, mapping by RNA-DNA hybridization and mapping of R-loops by electron microscopy. A degree of homology around 88 to $92 \%$ was estimated for the two serotypes using ten differents restriction enzymes. Restriction enzyme sites different between $\mathrm{Ad} 3$ and $\mathrm{Ad} 7$ genomes were found in the region encoding the fiber protein. Those authors postulate that genomic recombination could occur in nature giving rise to a hybrid virus that would be equally neutralized by antisera to Ad3 and Ad7. This hypothesis had been first put forward by Norby (1968) to explain one intermediate strain among Ad9/Ad15.

Adrian and Wigand (1986) studied the intermediate Ad3/Ad7 strain described by Matumoto et al. (1958) and they could not find mutations occurring in regions encoding proteins involved in neutralization sites (hexon, fiber or penton-base).

In this paper we were able to identify 16 regions corresponding to mutations in $\mathrm{Ad} 3 \mathrm{~h}$ genome in comparison with the prototype Ad3p. Three regions that are likely to contain neutralization determinants showed mutations: the L1 region encoding polypeptide IIIa, associated with hexon units that surround the penton, L3 region encoding polypeptides forming hexon and L5 region that encodes polypeptides forming the fiber.

Toogood et al. (1992) recognize that although several different epitopes in polypeptides forming hexon, fiber and penton base are involved in neutralization tests, some are more effective than others. Using monoclonal antibodies to Ad5 it was described 19 different epitopes in hexon, being one of this common to all adenovirus serotypes, another found also in Ad1 and Ad6 but not in Ad2 (Russell et al. 1981). If Ad3 and Ad7 have common epitopes, mutations affecting one epitope specific for Ad3 would change the neutralization pattern, as the specificity of the neutralization reaction seems to be controled by more than one specific epitope.
The restriction enzymes that we used in this study are the same used by Adrian and Wigand (1986) to study the intermediate Ad3/Ad7, with exception of $B c l$ I and $E c o$ RI that were not used by them. Just these enzymes showed one mutated site in fiber region (EcoRI) and one site mutated in hexon units that surround the penton $(B c I I)$. Although penton-base has few epitopes and than minor importance in neutralization, the hexon in opposite has several important epitopes. Ad3h presents three mutations in genome and these could perhaps enhance the effect on neutralization by Ad7p antiserum.

Any further explanation only would be possible by sequencing these regions of $\mathrm{Ad} 3 \mathrm{~h}$ and comparing with the sequencing of Ad3p and Ad7p. Our findings are in agreement with other authors that suggested the use of restriction enzyme patterns together with seroneutralization and hemagglutination inhibition tests for correct typing of adenovirus.

\section{ACKNOWLEDGMENTS}

To Dr Jean-Claude D'Halluin for kindly discussing and revising the manuscript. All standard adenovirus antisera and most of the adenovirus strains were a gift from Drs HG Pereira and MS Pereira (in memorian).

\section{REFERENCES}

Adrian TH, Wingand R 1986. Adenovirus 3-7 an intermediate strain of subgenus B. Intervirology 26: 202 206.

Adrian TH, Becker M, Hierholzer JC, Wigand R 1989. Molecular epidemiology and restriction site mapping of adenovirus 7 genome types. Arch Virol 106: 7374.

Adrian TH, Wadell G, Hierholzer JC, Wigand R 1986. DNA restriction analysis of adenovirus prototypes 1 to 41. Arch Virol 91: 277-290.

Broker TR 1984. Animal virus RNA processing, p.181212. In D Apirion, Processing of RNA, CRC Press, Boca Raton, Florida.

Fukumi H, Nishikawa F, Takemura M, Odaka Y 1961. Isolation of Adenovirus possessing both the antigens of type 3 and 7. Jap J Med Sc Biol 14: 173-181.

Garon CF, Berry KW, Hierholzer JC, Rose JA 1973. Mapping of base sequence heterologies between genomes from different adenovirus serotypes. $\mathrm{Vi}$ rology 54: 414-426.

Gomes SA, Candeias JAN, Monteiro SP, Pereira HG, Niel C 1989. New genome types 1, 3 and 5 isolated from stools of children in Brazil. J Clin Microbiol 27: $1022-1026$.

Hierholzer JC 1995. Adenoviruses, p.169-188. In EH Lennette, DA Lennette, ETLennette (eds), Diagnostic Procedures for Viral, Rickettsial and Chlamydial Infections, 7th ed., American Public Health Association, Washington.

Hirt B 1967. Selective extraction of polyoma DNA from infected mouse cell cultures. J Mol Biol 26: 365-369. 
Horwitz MS 1996. Adenovirus, p. 2149-2171. In BN Fields, DM Knipe, MD Howley (eds), Virology, 3rd ed., Lippincott Publishers, Philadelphia.

Kayon AE, Suarez MV 1990. Molecular epidemiology of adenovirus isolated from hospitalized children with acute severe lower respiratory infection in Santiago, Chile. J Med Virol 30: 294-297.

Kayon AE, Wadell G 1992. Characterization of Adenovirus genome type 7h: Analysis of its relationship to other members of serotype 7 . Intervirology 33 : 86-90.

Kayon AE, Murtagh PM, Franco SG, Freire MC, Weissenbacher MC, Zorzopulos J 1990. A new genome type of Adenovirus 3 associated with severe lower acute respiratory infection in children. $\mathrm{J} \mathrm{Med}$ Virol 30: 73-76.

Li QG, Wadell G 1986. Analysis of 15 different genome types of Adenovirus type 7 isolated in five continents. J Virol 60: 331-335.

Li QG, Wadell G 1988. Comparison of 17 genome types of Adenovirus type 3 identified among strains recovered from six continents. J Clin Microbiol 26: 1009-1015.

Matumoto M, Uchida S, Hoshika T, Matsuyama T 1958. Isolation of an intermediate type of adenovirus from a fatal case of infantile pneumonia. Jap J Exp Med 28: 305-315.

Niel C, Moraes MTB, Mistchenko A, Leite JPG, Gomes S 1991. Restriction site mapping of four genome types of Adenovirus types 3 and 7 isolated in South America. J Med Virol 33: 123-127.

Norby E 1968. Comparative studies on the soluble components of adenovirus types 9 and 15 and the intermediate strain 9-15. J Virol 2: 1200-1207.

Norby E 1969. The structural and functional diversity of adenovirus capsid components. J Gen Virol 5: 221236.

Nascimento JP, Siqueira MM, Sutmoller F, Krawczuk MM, de Farias V, Ferreira V, Rodrigues MJ 1991.
Longitudinal study of acute respiratory diseases in Rio de Janeiro: occurrence of respiratory viruses during four consecutive years. Rev Inst Med Trop São Paulo 33: 287-296.

Philipson L, Petterson U, Lindberg U 1975. Molecular biology of Adenovirus. Virol Mono 14: 1-115.

Rajafko RR 1967. Studies on serological relationships between strains of adenovirus types 3 and 7. Proc Soc Exp Biol Med 124: 580-585.

Rosen L 1960. A hemagglutination-inhibiton technique for typing adenovirus. Am J Hyg 71: 120-128.

Russel WC, Patel G, Precious B, Sharp I, Gardner PS 1981. Monoclonal antibodies against adenovirus type 5: preparation and preliminary characterization. $J$ Gen Virol 56: 393-408.

Tibbetts C 1977. Physical organization of subgroups B human Adenovirus genomes. J Virol 24: 564-579.

Toogood CIA, Crompton J, Hay RT 1992. Antipeptide antisera define neutralizing epitopes on the adenovirus hexon. J Gen Virol 73: 1429-1435.

Van Ormond H, Galibert F 1984. Nucleotide sequences of Adenovirus DNAs. Curr Top Microbiol Immunol 110: 73-142.

Wadell G, Cooney MK, Linhares AC, Silva L, Kennett ML, Kono R, Fang-Gui R, Lindman K, Nascimento JP, Schoub BD, Smith CD 1985. Molecular epidemiology of Adenovirus: global distribution of Adenovirus type 7 genome types. J Clin Microbiol 21 : 403-408.

Wadell G, de Jong JC 1980. Restriction endonucleases in identification of a genome type of adenovirus 19 associated with keratoconjunctivitis. Infect Immun 27: 292-296.

Wadell G, de Jong JC, Wolontis S 1981. Molecular epidemiology of Adenovirus: Alternating appearence of two different genotypes of Adenovirus 7 during epidemic outbreaks in Europe from 1958 to 1980. Infect Immun 34: 368-372. 
